\title{
Major Observations from a Specialized REU Program for Engineering Stu- dents with ADHD
}

\section{Dr. Arash Esmaili Zaghi P.E., University of Connecticut}

Dr. Arash E. Zaghi received his PhD in Civil Engineering from the University of Nevada, Reno, where he worked on the seismic behavior of novel bridge column and connection details. After graduating, he stayed with UNR as a Research Scientist to overlook two major research projects involving system-level shake table experiments. In 2011, Dr. Zaghi joined the Department of Civil and Environmental Engineering at University of Connecticut as an Assistant Professor. His research interests include: application of novel materials and systems for multi-hazard mitigation, design of bridges for extreme events and innovative repair techniques for aging bridges. Dr. Zaghi's research on next-generation bridge column systems and innovative bridge repair techniques was recognized by the American Society of Civil Engineers (ASCE). His latest research endeavor, however, is on the different subject of fostering creativity in engineering education focusing on potential and challenges of engineering students with ADHD. His research has been highlighted in Up Close of the Prism Magazine of American Society of Engineering Education.

\section{Prof. Mark Tehranipoor, University of Florida}

Mark M. Tehranipoor is currently the Intel Charles E. Young Professor in Cybersecurity at the Department of Electrical and Computer Engineering, the University of Florida. His current research projects include: hardware security and trust, electronics supply chain security, counterfeit IC detection and prevention, and reliable and testable VLSI design. Prof. Tehranipoor has published over 250 journal articles and refereed conference papers and has given more than 150 invited talks and keynote addresses since 2006. In addition, he has published six books and ten book chapters. His projects are sponsored by both the industry (Semiconductor Research Corporation (SRC), Texas Instruments, Freescale, Comcast, Honeywell, LSI, Mentor Graphics, Juniper, R3Logic, Cisco, Qualcomm, MediaTeck, etc.) and the Government (NSF, ARO, MDA, DOD, AFOSR, DOE, etc.).

He is a recipient of several best paper awards, the 2009 NSF CAREER award, the 2014 MURI award, the 2008 IEEE Computer Society (CS) Meritorious Service Award, the 2012 IEEE CS Outstanding Contribution, the 2010 IEEE CS Most Successful Technical Event for co-founding and chairing HOST Symposium, the 2009 and 2014 UConn ECE Research Excellence Award, and the 2012 UConn SOE Outstanding Faculty Advisor Award.

He serves on the program committee of more than a dozen leading conferences and workshops. Prof. Tehranipoor served as the guest editor for JETTA, IEEE Design and Test of Computers, and IEEE Computer Society Computing Now. He served as Program Chair of the 2007 IEEE Defect-Based Testing (DBT) workshop, Program Chair of the 2008 IEEE Defect and Data Driven Testing (D3T) workshop, Co-program Chair of the 2008 International Symposium on Defect and Fault Tolerance in VLSI Systems (DFTS), General Chair for D3T-2009 and DFTS-2009, and Vice-general Chair for NATW-2011.

He co-founded a new symposium called IEEE International Symposium on Hardware-Oriented Security and Trust (HOST) (http://www.hostsymposium.org/) and served as HOST-2008 and HOST-2009 General Chair and continue to serve as Chair of the Steering Committee for HOST. He is also a co-founder of Trust-Hub (www.trust-hub.org). He served as associate Editor-in-Chief (EIC) for IEEE Design and Test of Computers from 2012-2014. He is currently serving as an Associate Editor for IEEE Design and Test of Computers, an Associate Editor for JETTA, an Associate Editor for Journal of Low Power Electronics (JOLPE), an Associate Editor for ACM Transactions for Design Automation of Electronic Systems (TODAES). He has served as an IEEE Distinguished Speaker and an ACM Distinguished Speaker from 2010-2013.

Prior to joining University of Florida, Dr. Tehranipoor served as the founding director of the Center for Hardware Assurance, Security, and Engineering (CHASE) and the Comcast Center of Excellence in Security Innovation (CSI) at the University of Connecticut. 
ASEE’s 123rd Annual • Conference \& Exposition • New Orleans, LA • June 26-29, 2016

Prof. Tehranipoor is a Senior Member of the IEEE, Golden Core Member of IEEE Computer Society, and Member of ACM and ACM SIGDA. He is also a member of Connecticut Academy of Science and Engineering (CASE).

\section{Miss Caitlin Nichole O'Brien, University of Connecticut}

Senior at the University of Connecticut pursuing a double major in Civil Engineering and Environmental Engineering. Originally from Grafton, Massachusetts. 


\title{
Major Observations From a Specialized REU Program for Engineering Students with ADHD
}

\begin{abstract}
Students with Attention Deficit Hyperactivity Disorder (ADHD) tend to experience the traditional education system differently than their peers. The engineering education system has yet to realize unique potential of these students and identify ways in which to handle these differences in order to keep them engaged and successful. Published literature suggests that individuals with ADHD have the potential of strong divergent thinking skills and unparalleled risk-taking. However, this group of students is significantly underrepresented in engineering programs; some work suggests that only $3 \%$ of college students with ADHD choose to study engineering. The current design of engineering education largely fails to provoke the interest of these students because of its overemphasis on lecture-based learning and its discouraging evaluation methods. To recognize the unique intellectual strengths of engineering students with ADHD and encourage them to continue in engineering careers, a specialized Research Experience for Undergraduates (REU) Site titled "REU Site: Research Experience in Cyber and Civil Infrastructure Security for Students with ADHD: Fostering Innovation" has been funded by the NSF Division of Engineering Education and Centers.
\end{abstract}

This paper presents the significant observations of the performance of these students in research environment and the findings from the evaluation of the program through pre- and post-program surveys. It was found that through several informal and formal peer-to-peer interaction opportunities, the participating students related to one another's similar experiences and struggles in school and everyday life. Their interaction with the PI, who has firsthand experience with ADHD, presented them with a different perspective about their ADHD. The specialized seminars related to ADHD challenges and potentials helped the students gain confidence in their abilities and realize the unique benefits they can offer to the advancement of the nation. The eight participating students became heavily engaged in hands-on research lab activities with no issues related to lack of attention or interest. The majority of the participants intellectually contributed to their research projects, at a level comparable to advanced graduate students. In general, the participating students became more interested in engineering and desired to continue conducting research after the program's conclusion and pursue graduate studies. This experience clearly demonstrated that, in a properly designed education system based on learning-by-doing, students with ADHD might outperform their peers without ADHD-related impairments. This program intends to establish that ADHD may be perceived as a unique strength, not a disability.

Key Words: Creativity, Risk Taking, Divergent Thinking, ADHD, Research Experience, REU 


\section{Introduction}

Managing the risks from significant threats and hazards to cyber and critical infrastructure requires an integrated approach across diverse engineering disciplines. Interdependencies in civil infrastructure systems and their ever-increasing dependency on cyber systems for their communication, control, and monitoring, demand interdisciplinary research that crosses traditional boundaries between academic disciplines. As long as we treat cyber and civil infrastructure systems in isolation, we will not be able to accurately and comprehensively identify vulnerabilities and design effective mitigation strategies to enhance the security of these systems. Groundbreaking technological innovations play a crucial role in our nation's ability to face these significant challenges and ensure the global competitiveness of our nation. While incremental advancements have led to gradual technological progress, the magnitude of some of these challenges demands radical solutions proposed by creative and risk-taking minds. Historically, engineering and other science fields have not rewarded creativity, and it has been found that innovative thinkers are three times more likely to drop out of engineering courses than conventional thinkers.

Published literature supports the idea that individuals with ADHD may have the potential to be more creative than their peers. ${ }^{1-5}$ Their ability to be spontaneous and divergent thinkers allows them to take more risks. As they naturally tend to think outside of the box, individuals with ADHD have the potential to offer unexpected solutions to complex problems. ${ }^{6}$ Recent research findings suggest that: "We can find among the leaders of "notable" fields such as politics, science, and business, extremely creative people, often having reached the apex of their careers because of an ability to think creatively... the ability to apply such creative thoughts to practical life developed during childhood. Indeed, there has been speculation that individuals in human history who have exhibited particularly extraordinary creativity, but were considered poor students in childhood-Edison, Twain, Churchill, Dali, Einstein-would be diagnosed with ADHD today." "7 Thus, attracting this group of students to participate in engineering programs may significantly benefit the nation by increasing the number of engineers and researchers that are capable of making revolutionary advancements.

Despite the significant contribution ADHD students can make, they often struggle in traditional educational environments. Mainly, how the traditional educational setting functions does not cater to how students with ADHD achieve success, nor do teachers have sufficient training and understanding of how ADHD affects learning and academic performance. ${ }^{8}$ In current education systems, students with ADHD are less engaged during instruction, display more off-task and disruptive behavior, and are less academically motivated. There is a direct association between academic achievement and attention during instruction, indicating that students with ADHD can have more negative academic outcomes. ${ }^{8}$ This idea is reflected throughout college. College students with ADHD maintain lower GPAs, "withdraw from a greater number of courses" and complete their degree programs in a longer period of time. ${ }^{9}$ Based on a study by Anastopoulos et 
al., 9.1\% of students that display ADHD characteristics in young adulthood graduate from college while students that do not display ADHD characteristics have a $60.6 \%$ graduation rate. ${ }^{9}$ Intellectual differences do not seem to play a role in the difference between ADHD and nonADHD students, as published results have shown that the distribution of IQ level in individuals diagnosed with ADHD is similar to that of the normal population. It can then be argued that IQ is not a reason why individuals with ADHD are significantly underrepresented in engineering disciplines. A study examining a sample of college students with ADHD found that only $3 \%$ these students were in engineering programs, while $76 \%$ were enrolled in colleges of arts and sciences. $^{10}$

To embrace the significant minority of ADHD students in engineering programs, a specialized Research Experience for Undergraduates (REU) Site titled "REU Site: Research Experience in Cyber and Civil Infrastructure Security for Students with ADHD: Fostering Innovation" has been funded by the NSF Division of Engineering Education and Centers. The REU Site offers research opportunities in the security of critical infrastructures to undergraduates with ADHD. This program is designed based on unique strengths in divergent thinking and risk taking. This paper discusses the major observations of the REU program as well as the survey data collected from the eight participants before starting the program and after the program's completion during the summer of 2015 .

It was observed that the eight participating students became significantly engaged in hands-on research lab activities with no issues related to lack of attention or interest. The majority of the participants made notable intellectual contributions to their research projects. The analysis of the survey data demonstrated that this research experience helped the students by improving their confidence in their academic and professional capabilities and increasing their interest in engineering and pursuing graduate studies. It was found that peer-to-peer interaction as well as interaction with the Principle Investigator (PI) of the project, who has firsthand experience with ADHD, helped them realize the advantages of ADHD and reinforced their self-confidence.

\section{Background}

\section{Creative Potential of Students with ADHD}

Intelligence is most often used to advance existing societal agendas, whereas creative thinking often opposes these agendas and proposes new ones. Interestingly, many "symptoms" of ADHD are actually synonymous with highly creative qualities in individuals. Baum and Owen noted that, "the definitions of creativity and ADHD are oddly similar." 11 Cramond also shared this thought and stated that one must, "look carefully at behaviors exhibited by children for what may be potentialities instead of deficiencies." ${ }^{2}$ We suggest that the potentialities of students with ADHD are often ignored, particularly in engineering disciplines. Additionally, many educators focus on the label of disabled and do not approach students with ADHD using a strength-based model. Research suggests that using a strength based approach where highlighting the strengths 
and abilities instead of the challenges of a student may be more effective at keeping students

engaged and active in their learning, and allows the students' gifts and talents to be displayed. ${ }^{6,11}$

The research regarding the brain structures and functioning of those with ADHD has been furthered by the suggestion that those with ADHD actually help advance societies and are not simply a genetic coincidence. Williams and Taylor suggest that the prevalence of ADHD and the fact that the seven-repeat allele of DRD4 (dopamine receptor type D4) is positively selected in evolution, indicates that individuals with ADHD aid the evolution of society. The authors also emphasize that those with ADHD often engage in risk-taking and cognitive idiosyncrasy, thus benefiting society. Specially, Williams and Taylor state that, "we have suggested two advantages of ADHD-HI to society: first, increased exploration of behavioral possibilities and second, the confining of concomitant social and physical risk to a minority." 13

\section{Learning Potential in a Non-Traditional Educational Setting}

As previously discussed, the traditional educational setting can be detrimental to the academic success of ADHD students. Research carried out by Sungur et al. found that students in a nontraditional, problem-based learning environment, where they worked with real-life examples, had more advanced goal orientation, task value, use of learning strategies, critical thinking, selfregulation, effort, and peer learning, when compared to the control-group of students who were taught in a traditional, textbook-oriented setting. Academics have gradually shifted from a teacher-oriented approach to a student-oriented approach, encouraging more independent learning or self-regulated learning. How students become motivated and independent learners relies heavily on how the classroom and teaching is structured. ${ }^{14}$ Self-regulated learning is a form on non-traditional education that allows the student to take control of the learning process. Learning is not completely dependent on how the student responds and reacts to instruction. It engages students in decision-making process and helps them develop self-regulation and selfmonitoring skills. ${ }^{15}$

The NSF REU Site was structured to cater to the needs of its ADHD participants as well as incorporate a self-regulated learning environment not commonly found in traditional engineering education. This was done by engaging the students in research concerning real-life challenges related to cyber and civil infrastructure security. Working with mentors and peers allowed them to independently develop the knowledge and skills needed to study these problems and design and present innovative solutions.

\section{Structure of the NSF REU Site}

The program combined a ten-week traditional summer REU research experience with close mentorship, special seminars, brainstorming sessions, meetings, and workshops designed to address the needs and challenges of the ADHD participants. The specific objectives of this REU Site were to: 
- Provide an in-depth undergraduate research experience in a project related to cyber or physical infrastructure security while promoting the importance of an interdisciplinary view of security for interconnected, interdependent, and complex infrastructure.

- Promote advances and capacity by increasing the number of individuals with interdisciplinary expertise in cyber and physical security of critical infrastructure.

- Promote creativity as an essential component in security-related problem solving by encouraging approaches that are novel, transformative, and multidisciplinary.

- Capitalize on the strengths of an underserved group of students by encouraging students with ADHD to pursue research and advanced study in engineering disciplines.

- Increase the participation of a significantly underrepresented group of students who have the potential to profoundly impact the field, but are at high risk of academic failure.

- Understand the educational interests and demography of ADHD engineering students by analyzing the recruitment data, including number of applicants, academic majors, GPA, and research interests.

In addition to a focused research project throughout the program, the program incorporated afternoon laboratory rotations that both reflected the multidisciplinary characteristics of the critical infrastructure security problems and addressed the often-limited attention span of the ADHD student. The extended laboratory research experience allowed the students to form an indepth understanding of a critical infrastructure research challenge related to their academic majors. The students' daily schedule, then, consisted of spending mornings and early afternoons in their primary lab and afternoons in their laboratory rotation. Primary laboratory experiences were facilitated both by a graduate student and a faculty mentor. The rotations lasted for one week, which maintained student interest that can often be lost while spending extended periods of time on a single subject. They also gave students the opportunity for a meaningful introduction to the work in another engineering lab so that they could begin to make connections among the infrastructure components being investigated in the program. These eventual connections as well as the students' unique abilities to think outside-the-box and come up with creative, interdisciplinary ideas allowed them to contribute their thoughts and suggestions to one another's projects.

Their aptitude for creative thinking was also utilized during brainstorming meetings. Given a complex, atypical proposition or problem, students were given the opportunity to share their thoughts during stimulating discussions and develop innovative ideas. With great effort to have no interference in these discussions, the PI or a dedicated undergraduate assistant attended these sessions and took notes. The undergraduate assistant was also critical in providing support and maintaining order and timeliness among the students on a day-to-day basis, as well as facilitating various activities, workshops, and events that occurred during the program. The seminars and workshops that were offered throughout the program were presented by experts in their 
respective fields. The subjects of the seminars included twice-exceptional education and the creative product. Workshops were presented on responsible conduct of research and ethics, graduate school and preparing for the GRE exam, and technical writing. These activities were effective in expanding the students' knowledge of possibilities after undergraduate education and preparing them for the research they participated in throughout the summer.

\section{Observations and Survey Data}

\section{Demography of Participants}

To ensure that participants had enough experience in engineering fields to conduct research, as well as being ready to think about graduate school, the program was aimed towards college undergraduate juniors and seniors in engineering related majors. The demographic resulted in three female students and five male students. Among these eight participants, three were seniors, four were juniors, and one was a sophomore. All participants majored in engineering, but concentrations varied. Concentrations included four civil and environmental engineering students, two electrical engineering students, one mechanical engineering student, and one engineering physics student. Half of the students were from the home institution, the University of Connecticut. The other half were from institutions around the country, including Washington and Lee University, Virginia Commonwealth University, Virginia Polytechnic Institute and State University, and Binghamton University. It was understood that engineering students with ADHD might be struggling with grades in school. Therefore, GPA was not factored heavily into acceptance in the program. Their GPAs varied from 2.55 to 3.84, with a mean of 3.16.

\section{Data Collection}

Qualitative and quantitative data was collected throughout the program. Most qualitative data was collected during unstructured, casual discussions. Students were comfortable to discuss their opinions with the undergraduate assistant, who took notes throughout the discussions. Quantitative data was collected via formal pre- and post-program surveys. The survey was administered online a week prior to the program, as well has a month following the program. There were thirty survey questions in a six-point Likert scale or open-response format. The questions were related to academics, engineering, interest in graduate school, and how ADHD affected their daily life and college experience. The purpose of the survey was to improve the program as well as to see how the program affected the students. The students gave verbal consent that the general observations throughout the program may be disseminated through publications.

\section{Performance in the Research Labs}

The participants stayed fully engaged in their research projects and produced meaningful research results. Despite the steep learning curve that came with the challenging subjects for an undergraduate level, the students achieved valuable knowledge about their respective research 
topics. They gained understanding of the concepts for designing and performing experiments, compiling and organizing data, and presenting their findings in presentations and technical papers. By mid-program, most students delivered high quality presentations regarding their progress. At the end of the program, the research projects were presented in a poster session. The session was positively received by staff members from the office of the Dean of the School of Engineering, the faculty, and the students, as they were impressed with the quality of work and research delivered during an approximate eight-week period. Some students expressed their desire to continue their research projects following the end of the program and proceeded to do so. Additionally, each student had the opportunity to submit their findings to a conference of their choosing.

\section{Experiences of the Participants in Daily Life and Engineering Programs}

Through periodic roundtable discussions, the participants comfortably shared their ADHD related experiences in school and everyday life. Often times they were able to relate to one another and give thoughtful advice and suggestions. As an example, one major topic discussed was sleeping habits. The majority of the participants experienced difficulty trying to fall asleep and wake up in the morning. For some it could take hours to sleep, especially if their mind was stuck on unfinished work. Another topic the students frequently related to was the effects of stress in their daily lives. Many felt that even the simplest tasks brought them anxiety and they feared they would not be able to complete them. These fears often lead them to putting off doing the work, which lead to negative ramifications at times. There was a common difficulty with staying engaged in courses that were not interesting for them to the participants. They struggled in their general education classes because the subjects were not something they were passionate about. However, it was expressed that they still found it hard to stay focused in classes that they did find interesting. Participants found classes more engaging when learning with hands-on activities and projects instead of traditional, lecture-based learning. The students found difficulty in learning subjects without understanding how they apply to the "real world" and the grand scheme of their major's nature. It was agreed among the students that it was helpful to look at the big picture of whatever they were learning and then break it down into its individual

parts. For example, instead of learning formulations, it will be ideal to visualize the subject as a whole, and then learn reasoning for the need of formulations. These discussion sessions were deemed very beneficial for the students as it was reflected as such in the survey data.

\section{Survey Data}

The analyses of the responses to a set of eleven questions from the pre- and post-program surveys are presented in this paper. The Likert scale questions were converted to ordinal data and the mean and standard deviation of each survey question pre- and post-program was calculated. Selected questions of interest are depicted in Fig. 1. 
Pair 1: I may drop out of my engineering program.

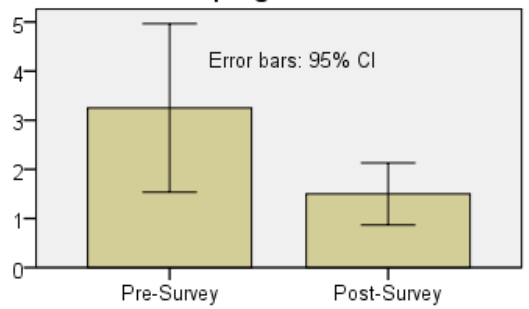

Pair 4: Importance of supportive friends in your academic success.

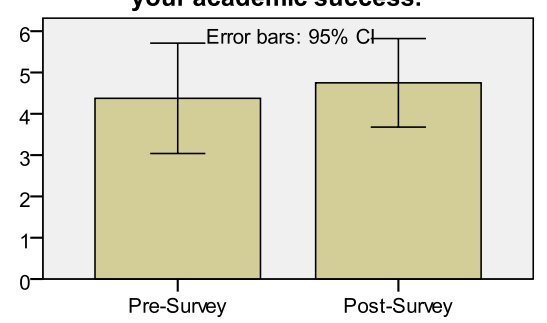

Pair 7: I view my ADHD as an advantage.

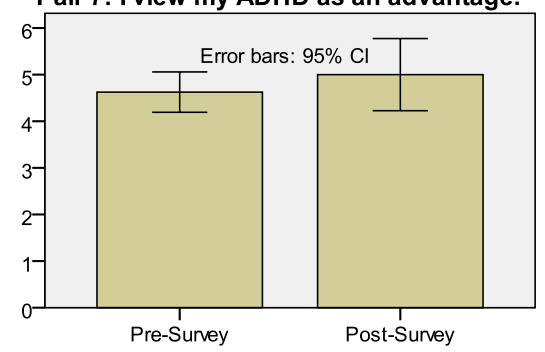

Pair 2: Attending this REU program will increase/has
increased my interest in pursuing graduate studies.

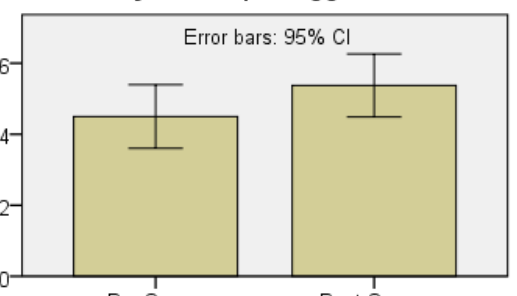

Pre-Survey

Post-Survey

Pair 5: Interacting with peers who also have ADHD will improve/ has improved my self-

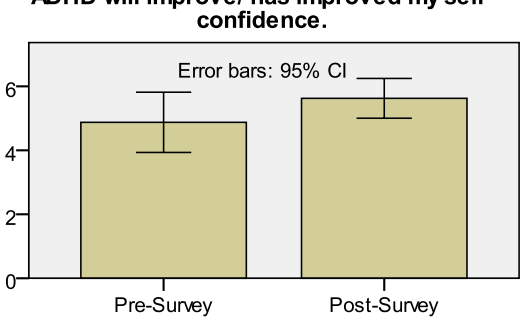

Pair 8: I am capable of making transformational

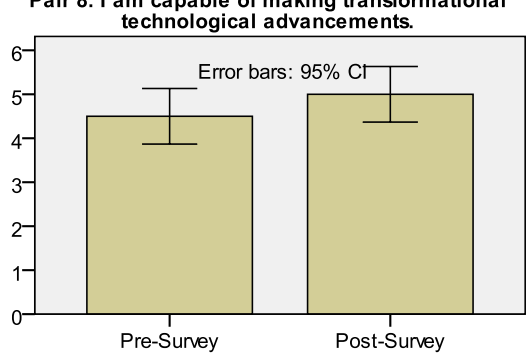

Pair 3: I am confident that I will find an engineering job after I graduate.

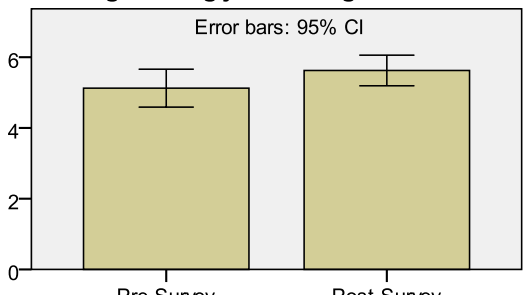

Pre-Survey

Post-Survey

Pair: 6: Interacting with the Principal Investigator who also has ADHD will improve/ has improved my self-confidence.

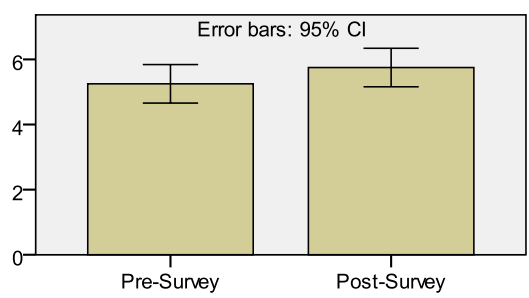

Pair 9: Getting involved in a research project will improve/has improved my interest in engineering.

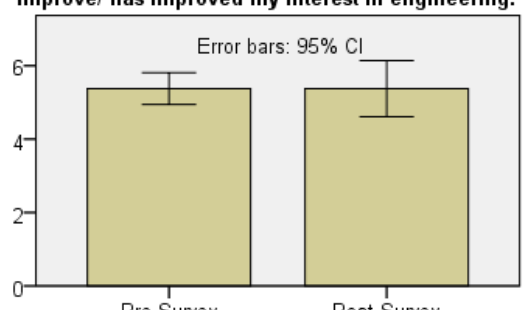

Pre-Survey Post-Survey

Pair 10: I have the potential to become an inventor.

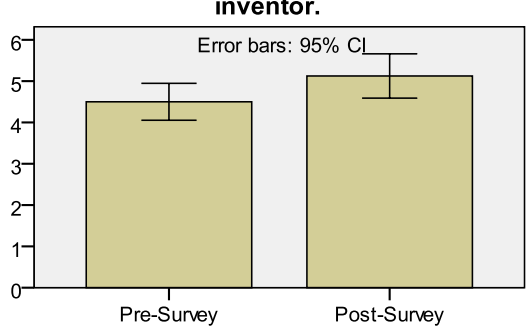

Pair 11: This program will help/ helped me reinforce my strengths.

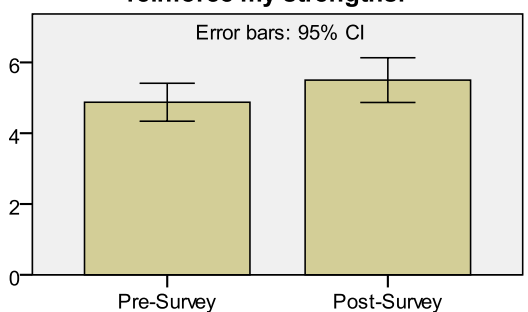

Fig. 1: Bar Charts for Eleven Selected Survey Questions Administered before and after the Program 
The results indicated that students were less likely to drop out of their engineering program, were more interested in attending graduate school, were more confident in themselves and their ability to perform in school, and had an overall positive experience attending the program. Wilcoxon Signed Ranks Test was used to compare the survey responses before and after the program (Table 1).

Initially, less than half of the participants either somewhat or strongly disagreed that they would drop out of their engineering program (Pair 1). After participating in the REU Site, all eight participants somewhat disagreed, disagreed, or strongly disagreed. When asked the likeliness that the students would pursue graduate studies (Pair 2), only one student had a more negative response Post-Survey. Three students had a more positive response when asked about their confidence in finding a job post-graduation (Pair 3).

Regarding Pairs 5, 6, 8, and 11, half of the students answered more positively post-survey. There was a higher agreement that interacting with the students who have ADHD as well as the PI who has ADHD would improve their self-confidence. The participants found themselves in higher agreement that they were capable of making technological advances and that the program reinforced their strengths. Five more students even found themselves in higher agreement that they had the potential to become inventors (Pair 10). There was an increase in the mean response for Pairs 4 and 7 . The participants agreed more on average that supportive friends are important in their academic success (Pair 4) and that they viewed their ADHD as an advantage (Pair 7).

The final question was a Yes or No question regarding whether the participants felt comfortable discussing their ADHD with their peers. Before attending the program, only half of the participants felt comfortable openly discussing their ADHD with their peers. After the program, 6 felt they were able to openly discuss it with their peers. 
Table 1: Wilcoxon Signed Ranks Tests addressing survey questions pre- and post-program.

\begin{tabular}{|c|c|c|c|c|}
\hline \multicolumn{2}{|l|}{ Pairs (Pre-Program - Post-Program) } & \multirow{2}{*}{$\frac{N}{5^{a}}$} & \multirow{2}{*}{$\frac{\text { Mean Rank }}{3.00}$} & \multirow{2}{*}{$\frac{\text { Sum of Ranks }}{15.00}$} \\
\hline 1. I may drop out of the engineering program. & Negative Ranks & & & \\
\hline & Positive Ranks & $0^{\mathrm{b}}$ & .00 & .00 \\
\hline & Ties & $3^{\mathrm{c}}$ & & \\
\hline & Total & 8 & & \\
\hline \multirow{4}{*}{$\begin{array}{l}\text { 2. Attending this REU program will } \\
\text { increase/has increased my interest in graduate } \\
\text { studies }\end{array}$} & Negative Ranks & 1 & 3.00 & 3.00 \\
\hline & Positive Ranks & 5 & 3.60 & 18.00 \\
\hline & Ties & 2 & & \\
\hline & Total & 8 & & \\
\hline \multirow{4}{*}{$\begin{array}{l}\text { 3. I am confident I will find an engineering job } \\
\text { after I graduate. }\end{array}$} & Negative Ranks & 0 & .00 & .00 \\
\hline & Positive Ranks & 3 & 2.00 & 6.00 \\
\hline & Ties & 5 & & \\
\hline & Total & 8 & & \\
\hline \multirow{4}{*}{$\begin{array}{l}\text { 4. Importance of supportive friends in academic } \\
\text { success. }\end{array}$} & Negative Ranks & 1 & 1.50 & 1.50 \\
\hline & Positive Ranks & 2 & 2.25 & 4.50 \\
\hline & Ties & 5 & & \\
\hline & Total & 8 & & \\
\hline \multirow{4}{*}{$\begin{array}{l}\text { 5. Interacting with peers who also have ADHD } \\
\text { will improve/has improved my self-confidence. }\end{array}$} & Negative Ranks & 0 & .00 & .00 \\
\hline & Positive Ranks & 4 & 2.50 & 10.00 \\
\hline & Ties & 4 & & \\
\hline & Total & 8 & & \\
\hline \multirow{4}{*}{$\begin{array}{l}\text { 6. Interacting with the Principle Investigator } \\
\text { who also has ADHD will improve/has improved } \\
\text { my self-confidence. }\end{array}$} & Negative Ranks & 0 & .00 & .00 \\
\hline & Positive Ranks & 4 & 2.50 & 10.00 \\
\hline & Ties & 4 & & \\
\hline & Total & 8 & & \\
\hline \multirow[t]{4}{*}{ 7. I view my ADHD as an advantage. } & Negative Ranks & 2 & 3.00 & 6.00 \\
\hline & Positive Ranks & 4 & 3.75 & 15.00 \\
\hline & Ties & 2 & & \\
\hline & Total & 8 & & \\
\hline \multirow{4}{*}{$\begin{array}{l}\text { 8. I am capable of making transformational } \\
\text { technological advances. }\end{array}$} & Negative Ranks & 0 & .00 & .00 \\
\hline & Positive Ranks & 4 & 2.50 & 10.00 \\
\hline & Ties & 4 & & \\
\hline & Total & 8 & & \\
\hline \multirow{4}{*}{$\begin{array}{l}\text { 9. Getting involved in a research project will } \\
\text { improve/has improved self-confidence. }\end{array}$} & Negative Ranks & 3 & 3.50 & 10.50 \\
\hline & Positive Ranks & 3 & 3.50 & 10.50 \\
\hline & Ties & 2 & & \\
\hline & Total & 8 & & \\
\hline \multirow[t]{4}{*}{ 10. I have the potential to become an inventor. } & Negative Ranks & 0 & .00 & .00 \\
\hline & Positive Ranks & 5 & 3.00 & 15.00 \\
\hline & Ties & 3 & & \\
\hline & Total & 8 & & \\
\hline \multirow{4}{*}{$\begin{array}{l}\text { 11. This program will help/has helped me } \\
\text { reinforce my strengths. }\end{array}$} & Negative Ranks & 0 & .00 & .00 \\
\hline & Positive Ranks & 4 & 2.50 & 10.00 \\
\hline & Ties & 4 & & \\
\hline & Total & 8 & & \\
\hline \multirow{4}{*}{$\begin{array}{l}\text { 12. Do you feel comfortable discussing your } \\
\text { ADHD with your peers? }\end{array}$} & Negative Ranks & 5 & 3.00 & 15.00 \\
\hline & Positive Ranks & 0 & 0.00 & 0.00 \\
\hline & Ties & 3 & & \\
\hline & Total & 8 & & \\
\hline
\end{tabular}
a. Post-Survey < Pre-Survey
b. Post-Survey $>$ Pre-Survey
c. Post-Survey $=$ Pre-Survey 


\section{Discussing Survey Statistics}

The survey data reflects the goals achieved by the REU program. For the most part, the survey questions reflected an improvement in the self-confidence of the participants as well as their interest in attending graduate school post-graduation. Survey questions that did not follow this trend generally had the responses that had been hoped for in the pre-survey.

A main goal of the REU experience was in increase the participants' self-confidence. This is reflected in Pairs 1, 3, 5, 6, and 7. Participants were less likely to consider dropping out of their engineering program after the REU experience. The participants are more confident in finding a job in engineering after graduation when comparing the pre- and post-survey's means as well as the post-survey's smaller variance about the mean. This can be said for Pairs 5 and 6 as well. It is interpolated that participants agreed more post-survey that interacting with peers with ADHD as well as the PI increased their self-confidence. Even though the mean was already generally high pre-survey, there was a higher mean and smaller variance of the survey post-program survey.

One of the main goals of this REU program was to increase the interest of students in graduate studies (Pair 2). The likeliness of students to participate in graduate studies was generally high before the program. Before the program, only two participants were either somewhat unlikely or unlikely to pursue graduate studies in the field of engineering. Following the program, all students were either somewhat likely, likely, or extremely likely to pursue graduate studies in the engineering field. One student had a reduced interest after the program.

An objective of this program was to help the participants come to terms with their ADHD and not see it as a negative attribute. After the program, there was an increased agreement that the participants viewed their ADHD as an advantage after the program (Pair 7). Additionally, more participants felt comfortable discussing their ADHD among their peers. Pair 12 indicated that the program succeed in helping the participants discuss ADHD openly with peers. Five of the participants who gave answer "no" to this question before the program, responded "yes" in the post-program survey. Two participants that felt they could not discuss their ADHD with peers, their reasoning was either because they did not want to get harassed by others for their medicine or that they felt it was a personal medical issue they only felt comfortable discussing with those they are close to.

The desire to get creative, innovative students with ADHD more involved in making transformational technological advances were deemed successful via the statistically significant Pairs 8 and 9. Students agreed more that they were capable of such transformational technological advances and that they had the potential to become inventors. 
Overall, the REU program was beneficial to the students' strengths. There was a statistically significant increase in participant agreement that the program reinforced their strengths following the programs conclusion (Pair 11).

\section{Conclusions}

The Research Experience for Undergraduates at the University of Connecticut titled REU Site: Research Experience in Cyber and Civil Infrastructure Security for Students with ADHD: Fostering Innovation, embraced the minority amount of ADHD students enrolled in engineering related programs. The findings and observations from the REU Site reflect the significant contributions made by the eight participants of the program in research environments, as well as the change in perspective the students had from pre- to post-program. Through peer-to-peer interaction as well as the specialized seminars provided during the program, the students were able to recognize the unique benefits they can offer to the advancement of the nation, as well as gain confidence in their ability to complete their engineering undergraduate degrees and potentially continue their education through graduate school. These findings are backed with qualitative as well as quantitative data.

This experience demonstrates that in a properly designed education system and environment, students with ADHD can thrive in challenging subjects like engineering. They can also perceive their ADHD as strength, not a disability.

This REU Site will be continued at the University of Connecticut for the summers of 2016 and 2017.

\section{Acknowledgements}

This research was a part of a project funded by the National Science Foundation (NSF), Division of Engineering Education and Centers under the Award Number 1461165. Any opinions, findings, and conclusions or recommendations expressed in this material are those of the authors and do not necessarily reflect the views of the National Science Foundation. Special thanks are given to Dr. James Kaufman, Dr. Sally Reis, Dr. Susan Baum, Dr, Rachael Gabriel, Dr. John G. D'Angelo, and Mr. Brent Lewchik for their expertise during seminars and workshops. Assistance from Ms. Shannon McIntyre and Caitlin O'Brian is appreciated. 


\section{References}

1 Fugate, C. M., Zentall, S. S. \& Gentry, M. Creativity and Working Memory in Gifted Students With and Without Characteristics of Attention Deficit Hyperactive Disorder: Lifting the Mask. Gifted Child Quarterly 57, 234-246 (2013).

2 White, H. A. \& Shah, P. Uninhibited imaginations: Creativity in adults with AttentionDeficit/Hyperactivity Disorder. Personality and Individual Differences 40, 1121-1131, doi:http://dx.doi.org/10.1016/j.paid.2005.11.007 (2006).

3 White, H. A. \& Shah, P. Creative style and achievement in adults with attentiondeficit/hyperactivity disorder. Personality and Individual Differences 50, 673-677, doi:http://dx.doi.org/10.1016/j.paid.2010.12.015 (2011).

4 Abraham, A., Windmann, S., Siefen, R., Daum, I. \& Güntürkün, O. Creative Thinking in Adolescents with Attention Deficit Hyperactivity Disorder (ADHD). Child Neuropsychology 12, 111-123, doi:10.1080/09297040500320691 (2006).

5 Moon, S. M., Zentall, S. S., Grskovic, J. A., Hall, A. \& Stormont, M. Emotional and Social Characteristics of Boys with AD/HD and Giftedness: A Comparative Case Study. Journal for the Education of the Gifted 24, 207-247 (2001).

6 Roberts, K. Movers, Dreamers, and Risk-takers: Unlocking the Power of ADHD. (Hazelden Publishing, 2012).

7 Krautkramer, C. J. Beyond Creativity: ADHD Drug Therapy as a Moral Damper on a Child's Future Success. The American Journal of Bioethics 5, 52-53, doi:10.1080/15265160591002845 (2005).

8 Rogers, M. \& Meek, F. Relationships Matter: Motivating Students with ADHD through the Teacher-Student Relationship. Perspectives on Language and Literacy 41, 21 (2015).

9 Anastopoulos, A. D. \& King, K. A. A cognitive-behavior therapy and mentoring program for college students with ADHD. Cognitive and Behavioral Practice 22, 141-151 (2015).

10 Sparks, R. L., Javorsky, J. \& Philips, L. College students classified with ADHD and the foreign language requirement. Journal of Learning Disabilities 37, 169-178 (2004).

11 Baum, S. M., Owen, S. V. \& Dixon, J. To be gifted \& learning disabled. (Creative Learning Press Mansfield Center, CT, 1991).

12 Cramond, B. Attention-Deficit Hyperactivity Disorder and Creativity-What is the connection? The Journal of Creative Behavior 28, 193-210 (1994).

13 Williams, J. \& Taylor, E. The evolution of hyperactivity, impulsivity and cognitive diversity. $J R$ Soc Interface 3, 399-413, doi:10.1098/rsif.2005.0102 (2006).

14 Sungur, S. \& Tekkaya, C. Effects of problem-based learning and traditional instruction on selfregulated learning. The journal of educational research 99, 307-320 (2006).

15 Stefanou, C., Stolk, J. D., Prince, M., Chen, J. C. \& Lord, S. M. Self-regulation and autonomy in problem-and project-based learning environments. Active Learning in Higher Education 14, 109122 (2013). 